\title{
Tamil Nadu and the Diagonal Divide in Sex Ratios
}

SHARADA SRINIVASAN, ARJUN S BEDI

Between 1961 and 2001, India's 0-6 sex ratio has steadily

declined. Despite evidence to the contrary, this ratio is often characterised in terms of a diagonal divide with low 0-6 sex ratios in northern and western India and normal 0-6 sex ratios in eastern and southern India. While unexpectedly high rates of female infant mortality have been reported in Tamil Nadu, it is still regarded as lying outside the ambit of states with unusually low 0-6 sex ratios. Based on an analysis of patterns in sex ratio at birth, infant mortality rates and under-5 mortality rates for Tamil Nadu, this paper traces the development of daughter deficit in the state and examines the validity of the diagonal divide in sex ratios across India. We find evidence of daughter deficit in more than half the state's districts with a majority of the shortfall arising before birth. The evidence presented here, combined with earlier work on declining 0-6 sex ratios outside northwestern India, suggests that the diagonal divide is no longer an appropriate distinction.

We thank the Directorate of Public Health, government of Tamil Nadu for VES data, Anandhkumar for assistance, K Nagaraj, Sayeed Unisa and Sunita Kishor for information on data sources and a referee for comments.

Sharada Srinivasan (sharada@yorku.ca) is with York University, Canada and Arjun S Bedi (bedi@iss.nl) is with Institute of Social Studies,

The Netherlands.

\section{Introduction}

7 he phenomenon of missing women is well-established in India. Based on Census 2001, Klasen and Wink (2003) estimate that about 39 million women are missing. Underlying this estimate, the population sex ratio in India has declined from 972 in 1901 to 933 in 2001 and the o-6 sex ratio, that is, the proportion of girls to boys has declined from 976 in 1961 to 927 in 2001 (Table 1, p 57).

Various factors such as nutrition (Goodkind 1996), incidence of hepatitis-B virus (Oster 2005), and parental hormonal levels (James 1996), among others, may influence sex ratios at birth (SRB) and therefore the o-6 sex ratio. In the Indian context, Oster (2005) argues that, in part, the level of the unexpectedly masculine SRB may be driven by the incidence of hepatitis-B virus while Jayaraj and Subramanian (2004) argue that, in part, the declining trend in the female-male SRB may be attributed to improvement in women's health status. While these explanations may account for some of the inequality in sex ratios, the differential survival of girls and boys due to practices like infanticide, neglect, and sex selective abortion cannot be denied. For instance, based on an analysis of SRB, Jha et al (2006) find that about 10 million female foetuses may have been aborted during 1985-2001.

Conventionally, much of the daughter shortfall has been accounted for by states such as Punjab, Haryana and Delhi in the north and Gujarat and Maharashtra in the west. An early essay on India's demography (Visaria 1967) demonstrated that sex ratios were persistently lower (i e, more masculine) in the northern states, and higher in the south. More than a decade later, Sopher (1980: 296) commented that the "completeness of the regional dichotomy is impressive". Dyson and Moore (1983) confirmed this pattern and grouped the major Indian states into two broad demographic regimes divided by a diagonal line that approximated the contours of the Satpura hill range, extending eastward to join the Chhotanagpur hills of southern Bihar. Miller's (1989: 1232) analysis of changes in juvenile sex ratios between 1961 and 1971 confirmed the diagonal divide.

More recently, analysis of changes in the o- 6 ratio between 1991 and 2001 shows that, except for Lakshadweep, Sikkim, Mizoram, Tripura and Kerala, all states have registered a decline in the ratio, prompting the conclusion that "the traditional northsouth divide stands significantly modified" (Agnihotri 2003: 4351). For example, Agnihotri (2003) shows that the o-6 sex ratio for Orissa has declined from 971 in 1991 to 953 in 2001 and that in 2001, 12 districts had a 0-6 sex ratio lower than 952 as against two in 1991. ${ }^{1}$ A similar pattern is observed in other eastern states. 
Nine out of 18 districts in West Bengal have an urban o-6 sex ratio below 952 while it is 927 in Kolkata. Fourteen of 23 districts in Assam display an urban o-6 sex ratio less than 952.

Despite evidence that the diagonal divide may no longer be valid, there is a tendency to persist with this distinction. For instance, based on Census 2001 data on SRB, Bhat and Zavier conclude that the SRB in the southern and eastern states of India "is well

\begin{tabular}{|c|c|c|c|c|c|c|c|c|c|c|c|}
\hline Year & 1901 & 1911 & 1921 & 1931 & 1941 & 1951 & 1961 & 1971 & 1981 & 1991 & 2001 \\
\hline 1: Population Sex Ratio-India & 972 & 964 & 955 & 950 & 945 & 946 & 941 & 930 & 934 & 927 & 933 \\
\hline 2: Population Sex Ratio-Tamil Nadu & 1,044 & 1,042 & 1,029 & 1,027 & 1,012 & 1,007 & 992 & 978 & 977 & 974 & 986 \\
\hline 3:0-6 Sex Ratio-India & . & & . & . & . & . & 976 & 964 & 962 & 945 & 927 \\
\hline 4:0-6 Sex Ratio-Urban India & . & . & . & . & . & . & . & . & . & 935 & 903 \\
\hline 5:0-6 Sex Ratio-Rural India & . & . & . & . & . & . & . & & & 948 & 934 \\
\hline 6: 0-6 Sex Ratio-Tamil Nadu & . & . & . & . & $1,010^{a}$ & $999^{a}$ & 985 & 974 & 967 & 948 & 942 \\
\hline 7:0-6 Sex Ratio-Urban Tamil Nadu & . & . & . & . & . & . & . & . & . & 955 & 951 \\
\hline 8:0-6 Sex Ratio-Rural Tamil Nadu & . & & . & . & & & & & & 945 & 931 \\
\hline
\end{tabular}

Ratios are defined as number of females per 1,000 males. ${ }^{\text {a }}$-4 sex ratio, from Chunkath and Athreya (1997).

Sources: Figures are based on census data (a) Rows 1 and 2, from 1901 to 1961, Visaria (1969), (b) Rows 1 and 2, from 1981 to 2001, Planning Commission (2002), (c) Rows 3 and 6, Premi (2001), (d) Rows 4, 5,7 and 8, and (e) Census India, Issue 15 (2003), Office of the Registrar General, India. presented in this paper are based on 8,95,765 births recorded in Tamil Nadu in Census 2001.

In addition, we use various rounds of Vital Events Surveys (ves) conducted by the Directorate of Public Health (DPH) of Tamil Nadu for the birth years 1996 to 1999 and for the birth year 2003. These surveys track vital events at the district level. The data available in each ves, nine million individuals and about 1,74,00o births, may be contrasted with the sRs surveys which cover 3,55,00o individuals and 6,000-7,000 births in the state in each round. Each ves covers 3,00,00o individuals per district and provides data on SRB and infant deaths disaggregated by district and gender (for details see Athreya 1999). Information from VES 1996 to 1999 is pooled to provide SRB and IMR estimates for the late 1990 s within the range observed in normal circumstances". They also note that, "a line drawn diagonally separating south and eastern India from north and western India would neatly demark the two regions of low and high sRB. Except for some isolated pockets (such as around Salem district in Tamil Nadu)... (ibid: 2296, emphasis added)". However, even based on their definition of a normal range, between 943 and 971, the prevailing SRB of 935 in Tamil Nadu (919 in rural Tamil Nadu) and of 926 in Orissa, clearly falls outside the normal range. ${ }^{2}$ Similarly, Bhaskar and Gupta (2007) note that south and east India exhibit international patterns in child sex ratio as against the unbalanced sex ratios in the northern and western states. While noting that "pockets of south India are infamous for infanticide" (Patel 2007: 41, emphasis added), a recent book on sex selective abortion does not contain any essay on the prevalence of the practice in southern and eastern states.

Set against this background, this paper has three aims. First, to use data from Tamil Nadu to examine the validity of the diagonal divide, second, to use information on SRB, infant mortality rates (IMR) and under-5 mortality rates (U5MR) to analyse statelevel temporal patterns in daughter deficit and third, to provide a district-level analysis of daughter deficit. A district-level assessment highlights intra-state variations while analysis of the SRB, IMR and U5MR provides an estimate of the extent of pre-birth, early (within a year after birth) and late (between age 1 and 5) post-birth daughter deficit in Tamil Nadu. ${ }^{3}$

The following section of the paper describes the data, Section 3 discusses benchmarks established for assessing the deficit, Section 4 presents the extent of daughter deficit while the final section concludes.

\section{Data}

An intra-state assessment of daughter deficits requires districtlevel data on SRB, IMR, and U5MR. Indian data on vital events comes from the Sample Registration System (sRs), a countrywide annual survey of vital events covering 1.1 million households in each round. The sRs supports state-level but not district-level analyses. Fortunately, the 2001 Census provides, for the first time, districtspecific data on live births. Accordingly, the district-specific SRB while information from vEs 2003 is used to compute districtspecific IMR estimates for the early 20oos. Information on genderspecific U5MR is available only at the state-level and as discussed below, this information is combined with infant mortality data to compute estimates of mortality in the age group 1-5.

\section{Benchmarking and Measuring Daughter Deficits}

Daughter deficit, defined as the gap between the number of expected daughters and the number of daughters born or alive in a certain age group, may occur before birth, within a year after birth (early post-birth deficit) or in the age group 1-5 (late postbirth deficit). ${ }^{4}$ This section considers how these deficits may be identified and establishes an "expected" ratio against which prevailing ratios may be compared.

\section{Pre-Birth Daughter Deficit}

International evidence on expected SRB in countries without prebirth interference is available from several sources. Based on 240 years of Swedish data, Johansson and Nygren (1991), henceforth $\mathrm{JN}$, conclude that the SRB is "biologically very stable" and close to 952 females per 1,00o males. JN also analyse data from 12 other western industrialised countries for the period 1970-84 and conclude that the SRB in these countries conforms to patterns found in Swedish data. We updated these numbers using data from United Nations (2004) and computed SRB for all countries with a relatively complete civil registration system (at least 90\%) with 1,70,00o or more live births per year (about the number recorded in Tamil Nadu's ves) and with no record of pre-birth interference. The sRB for the set of 16 countries which satisfied these criteria lies between 932 and 965 with a weighted mean of 948.5 Clearly, there is variation in the SRB across countries but given the number of factors that may have a bearing on SRB, it lies in a narrow range.

In the Indian context, the expected SRB may be obtained by examining SRB at a time when accurate pre-birth sex selection must have been difficult. The earliest source that we have located is Ramachandran and Deshpande (1964), henceforth RD. Based on 1.93 million births in hospitals and health centres between 1949 and 1958, RD report an all-India SRB of 943 and based on 
$7,36,216$ births a SRB of 943 for south India. While hospital data reflect a small proportion of births, RD conclude that given their large sample size it is likely that the hospital sex ratio is a "valid indicator of the order of magnitude of the SRB for the population". While RD's figures are based on actual birth data, estimates of the Indian SRB based on the link between SRB and life expectancy at birth have been computed by Klasen and Wink (2003) and Sudha and Rajan (2003). Both report an expected SRB of 961-962.

To benchmark pre-birth daughter deficit, we work with the average of the (south) India-specific estimates of 943 and 962 . That is, we use 952 female live births per 1,00o male live births as the sex ratio which may be expected in India and Tamil Nadu in the absence of interference. Thus, pre-birth daughter deficit $\left(D D_{p r e}\right)$, defined as the gap between the number of expected girls and the number of girls born is calculated as,

$\mathrm{DD}_{\text {pre }}=\mathrm{N}_{\mathrm{m}} \mathrm{SRB}_{\mathrm{e}}-\mathrm{N}_{\mathrm{f}}$

$N_{m}$ and $N_{f}$ denote the number of live male and female births and $S R B_{e}$ denotes expected SRB.

\subsection{Early Post-Birth Daughter Deficit}

IMR, defined as mortality in the age group 0-365 days and expressed as infant deaths per 1,0oo live births is usually higher for males. Based on a review, Waldron (1983) concludes that, "in most available data males have had higher mortality than females during the first year of birth". JN (1991) analyse male and female infant deaths in several countries for the period 1976-84, and conclude that there is a "natural" ratio of 77 female deaths for every 100 male infant deaths. Based on data from United Nations (2004), and for the same set of countries that satisfy the criteria used to establish the SRB benchmark, we find that the ratio of female to male infant deaths ranges from 71 to 83 with a weighted mean of $76.5 .^{6}$

Working with a naturally occurring SRB of 952 females per 1,00O males and a potential range of 71 to 83 female infant deaths for every 100 male infant deaths, yields an expected female IMR of between 75 (71/o.952) and 87 (83/o.952)\% of the male IMR. Based on the weighted mean of the ratio of female to male infant deaths we define the expected female IMR as $80 \%$ of the male IMR (76.5/.952). Thus, early post-birth daughter deficit $\left(D D_{\text {epost }}\right)$ is written as,

$\mathrm{DD}_{\text {epost }}=\left\{\mathrm{FIMR}_{\mathrm{s}}-\left(\mathrm{o} .8 * \mathrm{MIMR}_{\mathrm{s}}\right)\right\} \mathrm{N}_{\mathrm{f}}$.

$F I M R_{S}$ and $M I M R_{S}$ are estimated female and male infant mortality rates, respectively. Alternatively, (2) may be written as,

$\mathrm{DD}_{\text {epost }}=\left\{\mathrm{FIMR}_{\mathrm{s}}-\mathrm{FIMR}_{\mathrm{e}}\right\} \mathrm{N}_{\mathrm{f}}$,

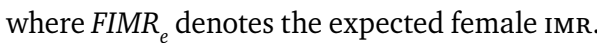

Post-birth deficit for Tamil Nadu is computed from ves based estimates (whereas pre-birth daughter deficit is based on census data). The ves data yield estimates of male and female IMR which help identify districts with evidence of early post-birth daughter deficit. However, an assessment of the absolute post-birth deficit, as in (3), requires information on the total number of female live births $\left(N_{f}\right)$. This information is only available from Census 20o1, while the IMR data are from vEs 2003. As long as there has been no major change in birth rates between this period, census information on the total number of female live births may be used to compute (3). According to SRS Bulletin ( $\mathrm{Vol} 36$, No 2), in 2001, the birth rate in Tamil Nadu was 19 per 1,00o while it was 18.3 in 2003 (SRS Bulletin, Vol 39, No 1). Both of these are surveybased estimates and it is unlikely that they are statistically different from each other, which suggests that information on female live births from Census 2001 may be used.

\subsection{Late Post-Birth Daughter Deficit}

To compute post-birth deficit in the age group 1-5 we need genderspecific mortality rates for this age group. While district level mortality rates for this age group are unavailable, state-level information on U5MR, at least for some years, is available and mortality rates for the age group 1-5 may be obtained by subtracting the IMR from the U5MR. ${ }^{7}$ However, before computing this rate we need to establish a benchmark for U5MR.

To establish this, we examined mortality patterns in the same set of countries used to establish benchmarks for SRB and IMR. Unfortunately, the various editions of the UN Demographic Yearbook contain information on age-specific mortality rates for the age group 0-4 and not for 0-5. While we are forced to use this information, it is unlikely that the male-female mortality gap in the two age groups differs substantially. Data on mortality patterns for these countries shows that the ratio of female to male deaths in the age group o-4 ranges from 72 to 83 female deaths for every 100 male deaths with a median of 78 and a weighted mean of 77 . These figures are similar to those obtained for defining the IMR benchmark and suggest that expected female mortality rate in the age group $0-5$ may also be pegged at about $80 \%$ of the male mortality rate. Thus, post-daughter deficit $\left(D D_{\text {lpost }}\right)$ in the age group 1-5 is defined as the gap between the estimated and expected female mortality rate, times the number of female births, and is written as,

$\mathrm{DD}_{\text {lpost }}=\left\{\left(\mathrm{FU}_{5} \mathrm{MR}_{\mathrm{s}}-\mathrm{FIMR}_{\mathrm{s}}\right)-\left(\mathrm{o} .8^{*}\left(\mathrm{MU}_{5} \mathrm{MR}_{\mathrm{s}}-\mathrm{MIMR}_{\mathrm{s}}\right)\right)\right\} \mathrm{N}_{\mathrm{f}} \ldots$...(4)

$F U_{5} M R_{s}$ and $M U_{5} M R_{s}$ are estimated female and male under-5 mortality rates. Alternatively, (4) may be written as,

$\mathrm{DD}_{\text {lpost }}=\left\{\mathrm{FCMR}_{\mathrm{s}}-\mathrm{FCMR}_{\mathrm{e}}\right\} \mathrm{N}_{\mathrm{f}}$,

where $F C M R_{s}$ and $F C M R_{e}$ are estimated and expected female child mortality rates in the age group 1-5.

Combining (1), (3) and (5), we obtain total daughter deficit (TD) as,

$$
\begin{aligned}
& \mathrm{TD}=\left(\mathrm{N}_{\mathrm{m}} \mathrm{SRB}_{\mathrm{e}}-\mathrm{N}_{\mathrm{f}}\right)+\left\{\mathrm{FIMR}_{\mathrm{s}}-\mathrm{FIMR}_{\mathrm{e}}\right\} \mathrm{N}_{\mathrm{f}}+\left\{\mathrm{FCMR}_{\mathrm{s}}-\mathrm{FCMR}_{\mathrm{e}}\right) \mathrm{N}_{\mathrm{f}} \\
& \mathrm{DD}_{\text {pre }} \quad \mathrm{DD}_{\text {epost }} \quad \mathrm{DD}_{\text {lpost }}
\end{aligned}
$$

\section{Estimates}

This section presents estimates of o- 6 and birth sex ratios as also the temporal and spatial patterns of infant mortality.

\subsection{Temporal and Spatial Patterns in 0-6 and Birth Sex Ratios}

We begin by discussing the figures in Table 1 . As shown there, between 1961 and 2001, the all India o-6 sex ratio fell from 976 to 927 , a decline of 49 points. Over the same period the o- 6 sex ratio 
in Tamil Nadu fell by 43 points from 985 to 942 . While the absolute level of the o-6 sex ratio in Tamil Nadu in 2001 is 15 points higher than the Indian o- 6 sex ratio and 144 points higher than Punjab (798) and 59 points higher than Gujarat (883), the decline in Tamil Nadu's o-6 sex ratio between 1961 and 2001 is clearly not very different from the all-India pattern.

While the overall trend in the o- 6 sex ratio in Tamil Nadu and India are similar, there are intriguing differences between urban Tamil Nadu and urban India. As Table 1 shows, in 1991, the o-6 sex ratio in urban Tamil Nadu was 955, 20 points higher than the corresponding number for urban India. While, in 1991, the o-6 sex ratio of 945 in rural Tamil Nadu was three points lower than the corresponding ratio in rural India. These differences persist in 2001. Between 1991 and 2001, Tamil Nadu's urban o-6 sex ratio declined by four points compared to a decline of 32 points for urban India, exacerbating the sex ratio gap between urban India and urban Tamil Nadu from 20 points in 1991 to 48 in 2001. In marked contrast, the 14-point decline in the $0-6$ ratio in rural Tamil Nadu from 945 to 931 is the same as the decline in rural India and Tamil Nadu's rural o- 6 sex ratio remains lower than the o-6 sex ratio for rural India. In fact, in 2001, Tamil Nadu is one of the few states in India where the rural o- 6 ratio is lower than the urban o- 6 ratio. ${ }^{8}$

Table 2 provides information on SRB for India and Tamil Nadu. Between 1978-92 and 2001 the Indian SRB fell from 943 to 909, a drop of 34 points. Over the same period, the Tamil Nadu SRB declined from 980 to 935 , a decline of 45 points. While the Tamil Nadu SRB is 26 points higher than the Indian SRB in 2001, it is lower than the expected sex ratio of 952 and the state's decline outpaces the country-wide decline in SRB. Similar to the patterns for the o- 6 sex ratio, there are differences between urban and rural Tamil Nadu. In 2001, the SRB was 960 in urban Tamil Nadu and 919 in rural Tamil Nadu.

\section{Figure: Pre-Birth Daughter Deficit, Tamil Nadu, Census 2001}

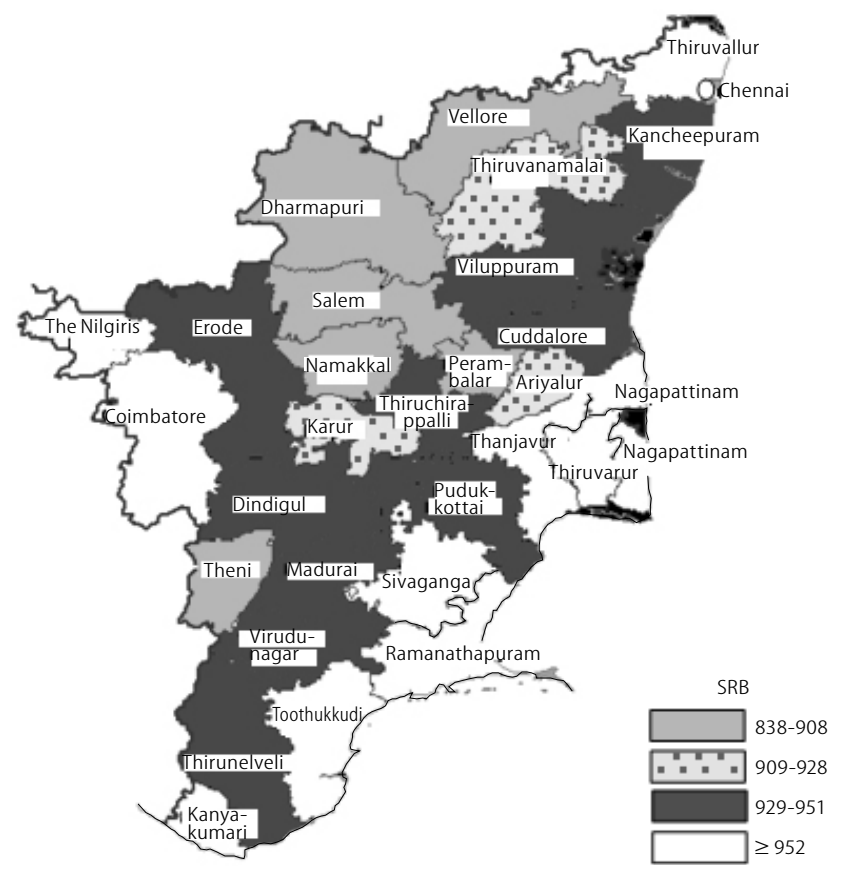

rural areas of 22 districts. While Salem has the lowest SRB of 838 , the idea that low SRB is restricted to certain pockets of the state around Salem district is incorrect. More than two-thirds of the rural parts of the various districts have SRB which are 4 to 146 points lower than the expected SRB and about a third of the urban parts of the various districts display SRB that are 1 to 72 points lower than the expected SRB.

\subsection{Temporal and Spatial Patterns in Infant Mortality}

Between 1981 and 2003 there is a sharp decline in overall IMR for Tamil Nadu (Table 4, p 60). In 1981 (Table 4, row 1), based on census estimates, Tamil Nadu's female IMR was 93 while male IMR was 114 . At 93, actual female IMR is slightly higher than the expected female IMR of 91.2 (o.8 times 114), suggesting limited incidence of early postbirth daughter deficit. IMR data from NFHS-1 for the period 1982-91 (Table 4, row 3) also reveals a similar pattern of higher male than female IMR (79 versus 63) and the estimated female IMR is lower than the expected female IMR of 63.2 (o.8 times 79), suggesting limited

Notwithstanding the differences between urban Tamil Nadu and urban India, the temporal analysis of the o- 6 sex ratio and the SRB clearly displays that the state is not an exception to the countrywide decline in these ratios.

Beyond statewide trends, Table 3 (p 6o) presents district-specific information on SRB. These estimates show that the SRB is lower than 952 in 19 of the state's 30 districts (see the figure). There are differences between urban and rural areas with evidence of prebirth deficit in the urban areas of "only" 10 districts as opposed to (no) incidence of early post-birth deficit. In contrast, while sRs 1981 also displays (Table 4, row 2) higher male IMR (93 versus 89), the gap between male and female IMR is not large and translates into an expected female IMR of 74.4 versus an estimated female IMR of 89 , suggesting a fairly high incidence (14.6 point gap) of early post-birth deficit.

While the sensitivity (to data source) of the extent of early post-birth deficit in the 1980s is a concern, for the 1990s and the 20oos, regardless of data source the gap between estimated and 
Table 3: SRB and Pre-Birth Deficit, Tamil Nadu, Census 2001

\begin{tabular}{|c|c|c|c|c|c|c|}
\hline & \multicolumn{2}{|c|}{ Overall } & \multicolumn{2}{|c|}{ Urban } & \multicolumn{2}{|c|}{ Rural } \\
\hline & $\begin{array}{l}\text { SRB } \\
\text { (1) }\end{array}$ & $\begin{array}{c}\text { Deficit } \\
\text { (2) }\end{array}$ & $\begin{array}{l}\text { SRB } \\
(3)\end{array}$ & $\begin{array}{l}\text { Deficit } \\
\text { (4) }\end{array}$ & $\begin{array}{c}\text { SRB } \\
(5) \\
\end{array}$ & $\begin{array}{c}\text { Deficit } \\
\text { (6) }\end{array}$ \\
\hline Tamil Nadu & 935 & 11,471 & 960 & 1,637 & 919 & 9,834 \\
\hline Ariyalur & 923 & 181 & 955 & 0 & 920 & 181 \\
\hline Chennai & 979 & 0 & 979 & 0 & & \\
\hline Coimbatore & 963 & 0 & 964 & 0 & 961 & 0 \\
\hline Cuddalore & 930 & 409 & 932 & 114 & 929 & 295 \\
\hline Dharmapuri & 869 & 2,212 & 936 & 58 & 859 & 2,154 \\
\hline Dindigul & 934 & 256 & 955 & 0 & 923 & 256 \\
\hline Erode & 934 & 362 & 962 & 0 & 910 & 362 \\
\hline Kancheepuram & 949 & 191 & 964 & 0 & 934 & 191 \\
\hline Kanyakumari & 988 & 0 & 1000 & 0 & 968 & 0 \\
\hline Karur & 910 & 296 & 941 & 272 & 895 & 24 \\
\hline Madurai & 951 & 228 & 973 & 0 & 925 & 228 \\
\hline Nagapattinam & 982 & 0 & 975 & 0 & 984 & 0 \\
\hline Namakkal & 859 & 885 & 916 & 119 & 829 & 766 \\
\hline Nilgiris & 988 & 0 & 963 & 0 & 1,023 & 0 \\
\hline Permabalur & 896 & 237 & 903 & 29 & 894 & 208 \\
\hline Pudukottai & 935 & 219 & 879 & 145 & 945 & 74 \\
\hline Ramanathapuram & 990 & 0 & 1019 & 0 & 981 & 0 \\
\hline Salem & 838 & 2,567 & 880 & 694 & 806 & 1,873 \\
\hline Sivaganga & 955 & 0 & 952 & 0 & 956 & 0 \\
\hline Thanjavur & 962 & 45 & 994 & 0 & 948 & 45 \\
\hline Theni & 895 & 444 & 924 & 114 & 862 & 330 \\
\hline Thirunelveli & 946 & 137 & 944 & 83 & 948 & 54 \\
\hline Thiruvallur & 953 & 170 & 971 & 0 & 936 & 170 \\
\hline Thiruvannamalai & 922 & 680 & 1,016 & 0 & 905 & 680 \\
\hline Thiruvarur & 967 & 0 & 999 & 0 & 960 & 0 \\
\hline Thuthukudi & 956 & 83 & 977 & 0 & 941 & 83 \\
\hline Tiruchirapalli & 951 & 111 & 964 & 0 & 941 & 111 \\
\hline Vellore & 907 & 1250 & 951 & 9 & 885 & 1,241 \\
\hline Villupuram & 938 & 328 & 955 & 0 & 936 & 328 \\
\hline Virudhunagar & 945 & 180 & 966 & 0 & 930 & 180 \\
\hline
\end{tabular}

Total state deficit is the sum of the deficit in each district. Total deficit for each district is the sum of deficits in the urban and rural parts of the district.

Source: Based on Census 2001, Table F-9.

expected female IMR lies in a narrow range. For instance, in 1991 (Table 4, rows 4 and 5), according to census-based estimates the gap between estimated and expected female IMR is seven points while it is six points on the basis of SRS 1991. During the rest of the 1990s, the three available data sources for the period reveal the presence of early post-birth daughter deficit with the gap between estimated and expected female IMR lying in a narrow range of 9.8 to 11.6 points (Table 4 , rows $6-8$ ).

For the early 20oos, female IMR dropped from 39 in the period 1996-99 to 29.7 by 2003 (Table 4 , row 9), but it was still higher than the expected female IMr of 24 . The difference of 5.7 points between the estimated and expected female IMR is statistically significant suggesting the continued presence of early post-birth daughter deficit in the 20oos. While statistically significant in both urban and rural areas, the gap is seven points in rural areas and relatively muted for urban areas where the gap is 1.8 points. While IMR figures based on SRs 2003 are higher than those based on VES 2003, a similar pattern of decline in female IMR from 53 in 1996 to 41 in 2003 (Table 4, rows 7 and 10) can be observed. The gap between estimated and expected female IMR in 2003 is about 5.8 points. Thus, regardless of data source the gap between estimated and expected female IMR are similar.

Beyond state-level patterns, district-specific numbers pre-

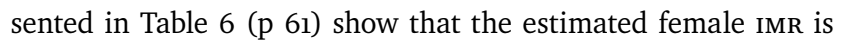
higher than the expected female IMR in nine districts. There is a large gap between urban and rural areas with evidence of early post-birth daughter deficit in the urban areas of one district as opposed to the rural areas of 10 districts.

\subsection{Sex Ratios and Sources of Daughter Deficit}

To examine the development of sex ratios up to age 6 and to identify the extent of daughter deficit occurring in each age group, consider the information on SRB, IMR, U5MR and the o- 6 sex ratio presented in Table 5 (p 61). Where possible we try to use data from a single source for each year. While the analysis is limited by data availability and is based on cross-section patterns (ideally one should follow a birth cohort over time) the figures are, nevertheless, revealing.

Consider Table 5, row 1, according to these figures, in 1981, the SRB in Tamil Nadu was 969 suggesting that there was no prebirth deficit at this time. Male IMR is pegged at 114 and female IMR at 93; given the higher male IMR this translates into a o-1 sex ratio of 989 . The male U5MR is 134 while it is 131 for girls, implying that in the age group $1-5$, the male mortality rate (U5MR-IMR) was far less than that for girls (20 per 1,00o male live births versus 38 per 1 ,ooo female live births). This 18 point gap translates into a decline in the o-1 sex ratio from 989 to the $0-5$ sex ratio of 968 . While, the decline from a SRB of 969 to a $0-6$ sex ratio of 967 suggests post-birth daughter deficit, the main insight is that, higher $1-5$ female mortality (1.9 times the male mortality) is the main source of daughter deficit. The gap between actual
Table 4: IMR in Tamil Nadu

\begin{tabular}{|c|c|c|c|c|c|c|c|c|c|c|}
\hline \multirow[t]{2}{*}{ Year/Statistic } & \multirow[t]{2}{*}{ Source } & \multicolumn{3}{|c|}{ Overall } & \multicolumn{3}{|c|}{ Urban } & \multicolumn{3}{|c|}{ Rural } \\
\hline & & Male & Female & $\begin{array}{l}\text { Expected } \\
\text { Female }\end{array}$ & Male & Female & $\begin{array}{l}\text { Expected } \\
\text { Female }\end{array}$ & Male & Female & $\begin{array}{c}\text { Expected } \\
\text { Female }\end{array}$ \\
\hline 1: 1981 & NHDR & 114 & 93 & 91.2 & . & . & . & . & . & \\
\hline 2: 1981 & SRS & 93 & 89 & 74.4 & . & . & . & . & . & \\
\hline 3: 1982-91 (mid-point 1986) & NFHS-1 & 79 & 63 & 63.2 & . & . & . & . & . & \\
\hline 4: 1991 & NHDR & 55 & 51 & 44 & . & . & . & . & . & \\
\hline 5: 1991 & SRS & 60 & 54 & 48 & 43 & 40 & 34.4 & 69 & 61 & 55.2 \\
\hline 6: 1989-98 (mid-point 1993) & NFHS-2 & 50.2 & 51.8 & 40.2 & . & . & . & . & . & \\
\hline 7: 1996 & SRS & 54 & 53 & 43.2 & 42 & 34 & 33.6 & 59 & 61 & 47.2 \\
\hline 8: 1996-99 & VES & 36 & 39 & 28.8 & 23 & 19 & 18.4 & 41 & 48 & 32.8 \\
\hline $\begin{array}{l}\text { Absolute value of test statistic } \\
\text { p-value }\end{array}$ & & & $\begin{array}{r}23.5 \\
(0.000) \\
\end{array}$ & & & $\begin{array}{r}1.01 \\
(0.313) \\
\end{array}$ & & & & $\begin{array}{r}26.8 \\
(0.000) \\
\end{array}$ \\
\hline 9:2003 & VES & 30 & 29.7 & 24 & 24 & 21 & 19.2 & 32.6 & 33.1 & 26.1 \\
\hline Absolute value of test statistic & & & 7.20 & & & 1.43 & & & 7.11 & \\
\hline$p$-value ${ }^{a}$ & & & $(0.000)$ & & & $(0.152)$ & & & $(0.000)$ & \\
\hline 10: 2003 & SRS & 44 & 41 & 35.2 & 32 & 31 & 25.6 & 44 & 41 & 35.2 \\
\hline
\end{tabular}

IMR-number of infant deaths (age 0-365 days) per 1,000 live births. ${ }^{\text {a }} \mathrm{H} 0$ : Estimated FIMR is equal to expected FIMR.

Sources: (a) Row 1 and row 4, Planning Commission (2002), (b) Rows 2, 5, 7 and 10, SRS Bulletins; Row 2 (Vol 19, No 1), rows 5 and 7 (Vol 31, No 1), row 10 (Vol 39, No 1), (c) Row 3, Pandey et al (1998), row 6, www.nfhsindia.org/data/tn/tnchap6.pdf, and (d) Row 8 and 9 are based on VES. 
and expected female U5MR is 23.8 (131-0.8*134), most of which is accounted for by deficit in the age group $1-5\left(38-0.8^{*} 20=22\right)$, while early post-birth deficit accounts for the remaining gap $(93-0.8 * 114=1.8)$. Thus, in 1981 these numbers suggest no prebirth daughter deficit; about $7 \%$ early post-birth daughter deficit and $93 \%$ late-post birth daughter deficit. ${ }^{9}$

In 1991 (Table 5, row 3) as in 1981, the SRB in Tamil Nadu was 952, suggesting no pre-birth daughter deficit. A male IMR of 55 and a female IMR of 51 translates into a o-1 sex ratio of 955 . The male U5MR is 64 while it is 70 for girls, implying that in the age group $1-5$ the male mortality rate was less than that for girls ( 9 per 1,0oo male live births versus 19 per 1,00o female live births). This 10 point gap translates into a decline in the o-1 sex ratio from 955 to 942 for the o-5 group, which becomes favourable to girls in the age group 5-6 to reach 948 for the age group o-6. The decline from a SRB of 952 to a o- 6 sex ratio of 948 suggests post-birth daughter deficit. The main point is that while the higher female $1-5$ mortality (2.1 times the male mortality) is still the main source of daughter deficit, its share has declined as compared to 1981 and early post-birth deficit has become higher than in 1981. The gap between actual and expected female U5MR is 18.8 (70-0.8*64), most of which is accounted for by deficit in the age group $1-5(19-0.8 * 9=11.8)$, while early post-birth deficit accounts for the remaining gap $(51-0.8 * 55=7)$. Thus, in 1991 these numbers suggest no pre-birth deficit, about $37 \%$ early post-birth deficit and $63 \%$ latepost birth deficit.

During 1996-99 (Table 5, row 5), unlike the previous years, the vEs-based SRB of 935 is well below the benchmark of 952 suggesting the presence of pre-birth daughter deficit. In contrast to 1981 and 1991, female IMR is higher than male IMR which translates into a less favourable o-1 sex ratio of 929. Since we do not have information on U5MR or the o-6 sex ratio for this period we cannot say more. Combining information from Census 2001 and SRs 2001 (Table 5, row 6) allows us to construct the situation in 2001. The SRB remains at 935, implying pre-birth daughter deficit; female IMR continues to be higher than male IMR translating into a o-1 sex ratio of 923 . In sharp contrast to 1981 and 1991, by age 6 the sex ratio rises to 942 . Thus, starting with a SRB of 935 and falling to a o-1 sex ratio of 923, the o-6 sex ratio has becomes favourable to girls, which in turn suggests that in 2001, unlike 1981 and 1991, male mortality between 1 and 6 is much higher than female mortality and that daughter deficit is unlikely to emanate from the age group 1-6. While we do not have figures for under-5 mortality, the increase in the sex ratio from (o-1) 923 to (o-6) 942 suggests that in 2001, male and female U5MR matches the internationally expected pattern of higher male mortality. Overall, these numbers show clear evidence of pre-birth and early post-birth daughter deficit and do not support a substantial role for late post-birth daughter deficit.

Beyond 2001, IMR data from SRS 2003 and VEs 2003 (Table 5, rows 7 and 8) is used to compute early post-birth deficit. Based on SRs 2003 , early post-birth daughter deficit is $5.8(41-0.8 * 44)$ and based on VES 2003 early post-birth daughter deficit is 5.7

\begin{tabular}{|c|c|c|c|c|c|c|c|c|}
\hline Year & SRB & MIMR & FIMR & $\begin{array}{c}0-1 \\
\text { Sex Ratio }\end{array}$ & $\begin{array}{l}\text { Under } 5 \\
\text { MMR }\end{array}$ & $\begin{array}{l}\text { Under } 5 \\
\text { FMR }\end{array}$ & $\begin{array}{c}0-5 \\
\text { Sex Ratio }\end{array}$ & $\begin{array}{c}0-6 \\
\text { Sex Ratio }\end{array}$ \\
\hline 1: 1981 & 969 & 114 & 93 & 989 & 134 & 131 & 968 & 967 \\
\hline 1: 1981 & 952 & 93 & 89 & 951 & . & . & . & . \\
\hline 1: 1991 & 952 & 55 & 51 & 955 & 64 & 70 & 942 & 948 \\
\hline 1: 1991 & 952 & 60 & 54 & 955 & . & . & . & . \\
\hline 5: 1996-99 & 935 & 36 & 39 & 929 & . & . & . & . \\
\hline 1:2001 & 935 & 45 & 54 & 923 & . & . & . & 942 \\
\hline 7: 2001(SRB) and 2003 (IMR) & 935 & 44 & 41 & 935 & . & . & . & . \\
\hline 8: 2001(SRB) and 2003 (IMR) & 935 & 30 & 29.7 & 934 & 34 & & & . \\
\hline
\end{tabular}

Sources: (a) Rows 1 and 3, Planning Commission (2002)-SRB figures are weighted averages of the rural and urban SRB, (b) SRB figures-row 2 and row 4, are SRS-based estimates for the period 1981-90 to 1996-98, Retherford and Roy (2003). IMR figures for 1981 and 1991 are from SRS Bulletin, Vol 19, No 1 and Vol 31, No 1, respectively, (c) Row 5, based on VES, (d) SRB figures, rows 6,7 and 8, Census 2001, Table F-9; IMR figures, rows 6 and 7, SRS Bulletin, Vol 37, No 1 and Vol 39, No 1, respectively, and (e) IMR figures, row 8 are based on VES; U5MR, Health Indicators 2003, Government of Tamil Nadu.

\begin{tabular}{|c|c|c|c|c|c|c|c|c|c|}
\hline & $\begin{array}{c}\text { MIMR } \\
\text { Overall }\end{array}$ & $\begin{array}{c}\text { FIMR } \\
\text { Overall }\end{array}$ & $\begin{array}{l}\text { Deficit } \\
\text { Overall }\end{array}$ & $\begin{array}{l}\text { MIMR } \\
\text { Urban }\end{array}$ & $\begin{array}{c}\text { FIMR } \\
\text { Urban }\end{array}$ & $\begin{array}{l}\text { Deficit } \\
\text { Urban }\end{array}$ & $\begin{array}{l}\text { MIMR } \\
\text { Rural } \\
\end{array}$ & $\begin{array}{l}\text { FIMR } \\
\text { Rural }\end{array}$ & $\begin{array}{c}\text { Deficit } \\
\text { Rural }\end{array}$ \\
\hline Tamil Nadu & 30 & 29.7 & 1,829 & 24 & 21 & 26 & 32.6 & 33.1 & 1,799 \\
\hline Chennai & 17 & 14 & 2 & 17 & 14 & 2 & . & . & . \\
\hline Coimbatore & 23 & 19 & 11 & 15 & 13 & 14 & 25 & 21 & 2 \\
\hline Cuddalore & 32 & 31 & 98 & 32 & 22 & 0 & 32 & 35 & 110 \\
\hline Dharmapuri & 39 & $40^{*}$ & $219^{*}$ & 21 & 16 & 0 & 45 & $49 *$ & $258^{*}$ \\
\hline Dindigul & 31 & $48^{*}$ & $289 *$ & 33 & 35 & 37 & 30 & $54^{*}$ & $241^{*}$ \\
\hline Erode & 32 & 25 & 0 & 26 & 18 & 0 & 34 & 28 & 3 \\
\hline Kancheepuram & 23 & 21 & 58 & 23 & 21 & 21 & 23 & 22 & 31 \\
\hline Kanyakumari & . & . & . & 26 & 11 & 0 & . & . & . \\
\hline Karur & 34 & 34 & 41 & 26 & 31 & 21 & 37 & 35 & 22 \\
\hline Madurai & 28 & $35^{*}$ & $230^{*}$ & 22 & 20 & 19 & 30 & $42^{*}$ & $138^{*}$ \\
\hline Nagapattinam & 32 & 29 & 40 & 25 & 26 & 14 & 34 & 30 & 24 \\
\hline Namakkal & 26 & 21 & 4 & 13 & 9 & 0 & 31 & 26 & 7 \\
\hline Nilgiris & 28 & 24 & 12 & 20 & 26 & 33 & 32 & 24 & 0 \\
\hline Permabalur & 31 & $38^{*}$ & $49^{*}$ & . & . & . & 31 & $38^{*}$ & $42^{*}$ \\
\hline Pudukottai & 28 & $30^{*}$ & $92^{*}$ & 20 & 19 & 6 & 31 & $35^{*}$ & $97^{*}$ \\
\hline Ramanathapuram & 34 & 31 & 36 & 27 & 31 & 22 & 37 & 31 & 11 \\
\hline Salem & 33 & $41^{*}$ & $283^{*}$ & 29 & 33 & 83 & 35 & $45^{*}$ & $178^{*}$ \\
\hline Sivaganga & 28 & 20 & 0 & 27 & 10 & 0 & 28 & 24 & 8 \\
\hline Thanjavur & 33 & 23 & 0 & 18 & 13 & 0 & 38 & 26 & 0 \\
\hline Theni & 33 & $39 *$ & $88^{*}$ & 28 & 31 & 31 & 35 & $42^{*}$ & $46^{*}$ \\
\hline Thirunelveli & 37 & 32 & 59 & 38 & 31 & 11 & 36 & 32 & 42 \\
\hline Thiruvallur & 25 & 22 & 35 & 16 & 15 & 25 & 28 & 24 & 13 \\
\hline Thiruvannamalai & 30 & 29 & 82 & 25 & 18 & 0 & 32 & 34 & 107 \\
\hline Thiruvarur & 28 & 21 & 0 & 13 & $26^{*}$ & $26^{*}$ & 34 & 19 & 0 \\
\hline Thuthukudi & 30 & 27 & 37 & 24 & 20 & 7 & 33 & 30 & 27 \\
\hline Tiruchirapalli & 29 & $37^{*}$ & $230^{*}$ & 30 & 24 & 6 & 29 & $42^{*}$ & $182^{*}$ \\
\hline Vellore & 33 & $40^{*}$ & $349^{*}$ & 24 & 20 & 1 & 36 & $48^{*}$ & $312^{*}$ \\
\hline Villupuram & 32 & 32 & 143 & 33 & 22 & 0 & 32 & $36^{*}$ & $195 *$ \\
\hline Virudhunag & 34 & 30 & 37 & 24 & 28 & 52 & 38 & 31 & \\
\hline
\end{tabular}

IMR- number of infant deaths (age 0-365 days) per 1,000 live births. The state total is based on districts where the difference between estimated and expected SRB is statistically different.* Indicates estimated FIMR is statistically greater than expected FIMR at at least $5 \%$ significance level.

Source: Based on VES 2003. 
$(29.7-0.8 * 30)$ as compared to a pre-birth daughter deficit of 17 in 2001 (based on SRB from Census 2001). While we do not have gender-specific U5MR for 2003, we do have information on overall U5MR. According to VES 2003, overall U5MR is $34 .^{10}$ Using weights based on the number of boys and girls at birth (0.52 and 0.48 , respectively) and based on the extreme assumption that as in 1981 and 1991 female mortality in the age group $1-5$ is twice that of male mortality leads to a male U5MR of 32.7 (that is, an IMR of 30 and an U5MR of 32.7) and a female mortality rate of 35.4 (an IMR of 29.7 and an U5MR of 35.4$).{ }^{11}$ The gap between estimated and expected female U5MR is 9.24 (35.4-0.8*32.7). Most of this gap is accounted for by daughter deficit in the age group o-1, $(29.7-0.8 * 30=5.7)$ while late post-birth daughter deficit accounts for the remaining gap $(5.7-0.8 * 2.7=3.54)$. Thus, based on this extreme assumption we get a late post-birth daughter deficit of 3.54, early post-birth daughter deficit of 5.7 and a pre-birth daughter deficit of 17 . These figures translate into a $65 \%$ share for pre-birth daughter deficit, $22 \%$ due to early post-birth daughter deficit and at most $13 \%$ to late post-birth daughter deficit. Even if we work with higher IMR figures from SRS 2003 (about 1.36-1.41 times VES 2003) and correspondingly assume a higher U5MR of 48 (about 1.4 times ves 2003) and continue with the assumption that, as in 1981 and 1991 female 1-5 mortality is twice that of male mortality, in terms of their relative shares, at most $15 \%$ of total daughter deficit may be attributed to late post-birth daughter deficit.
Overall, the state-level analysis reveals sharp temporal changes in the relative contributions to daughter deficit. Between 1981 and 2001 the contribution of late post-birth daughter deficit declines sharply, the share of pre-birth daughter deficit rises sharply while the share of early post-birth daughter deficit remains relatively stable. For the 1980 os and 199os, the data support a division of total daughter deficit into early and late post-birth deficit while for the latter half of the 1990s and early 20oos the data support a division of total daughter deficit into pre-birth and early postbirth daughter deficit.

\subsection{Spatial Patterns in Daughter Deficit}

Given the foregoing discussion, since the district-specific data are from the early 200os, we use a two part division of total daughter deficit into pre-birth and early post-birth deficit to compute district-level patterns. The total pre-birth daughter deficit in 2000 was 11,471 (Table 3), the bulk of which emanates from rural areas (about $86 \%$ of the shortfall). While there is evidence of deficit in rural areas of 22 districts, much of the deficit is concentrated in Salem (23\%), Dharmapuri (19.6\%), Vellore (11\%) and Namakkal (7.8\%). Estimates of early post-birth daughter deficit based on Census 2001 and ves 2003 data are provided in Table 6. The total estimated early post-birth deficit is 1,829 daughters, almost all of which may be attributed to the rural areas of the state. In terms of districts, early post-birth daughter deficit is more equally distributed with Vellore accounting for

\section{EPW Research Foundation (a unIт ов sамевкSна твичsт)}

C-212 Akurli Industrial Estate, Akurli Road, Kandivli (East), Mumbai - 400101

Tel: (022) 2885 4995/ 96 \& 2887 3038/41 | Fax:(022) 28873038 | Email: epwrf@vsnl.com | web: www.epwrf.res.in

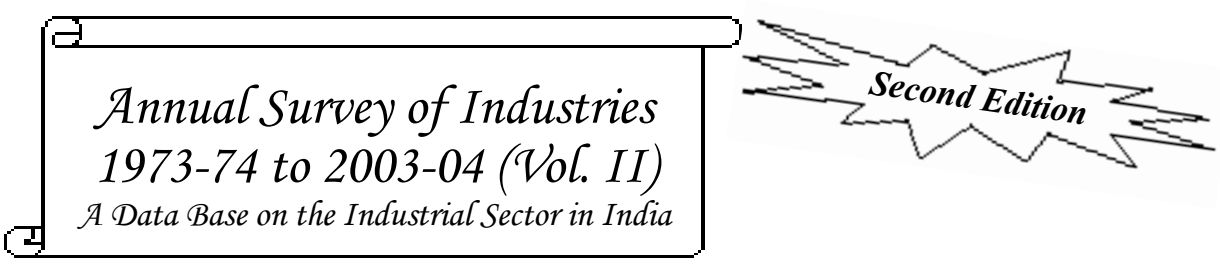

The EPW Research Foundation (EPWRF) has released the Second Edition of its study on the Annual Survey of Industries (ASI), thus extending its data base for 31 years from 1973-74 to 2003-04 in CD ROM. This study is one of the most coveted data base studies of the institution. This is considered useful for wide sections of professionals - research scholars at universities/colleges/institutes as also policy planners and company executives in India and abroad alike.

We hope that this revised data base work will facilitate more serious research on the nature of industrial growth in India in recent decades and its various dimensions. The $\mathrm{CD}$ containing the publication is priced per copy thus :

Inland

CD ROM

Foreign

Rs. 4,500*

US \$ 200

* Concessional rate of Rs. 2,500 for subscribers of the previous volume; so also for students and research scholars on

producing a brief evidence of their eligibility for concession along with the order.

NB: Some print versions of the First Edition are available for sale at a nominal price of Rs. 800 per copy.

CDs (and First Edition copies) can be obtained from:

\section{The Director, EPW Research Foundation}

C-212, Akurli Industrial Estate, Akurli Road, Kandivli (East), Mumbai - 400 101, INDIA.

Phones: (022) 2885 4995/4996 E-Mail: epwrf@vsnl.com

(Remittances by Demand Draft/Cheque or through online payment gateway. Demand Draft and Cheque are to be in favour of EPW Research Foundation payable at Mumbai. Outstation Cheques should include Rs 50/- as bank collection charges. For online payment, please visit our website: http://www.epwrf.res.in) 
$17 \%$ followed by Dharmapuri, Dindigul, Villupuram and Salem, accounting for between 10 and $14 \%$ each. Overall, pre-birth daughter deficit dominates, accounting for (in this two-part classification) about $85 \%$ of the total shortfall of about 13,000 daughters per year. As discussed above, even if we were to use a three-part classification, the conclusion that in the 2000 s the bulk (65\%) of daughter deficit may be attributed to pre-birth deficit remains unchanged.

\section{Conclusions}

This paper highlighted variations in the problem of daughter deficit in Tamil Nadu which a national-level analysis often misses. A temporal examination of the SRB, IMR, U5MR and the o-6 sex ratio showed that between 1981 and the early 2000 s there has been a sharp change in the source of daughter deficit.
Based on a division of daughter deficit into pre-birth, early (age group 0-1) post-birth and late (age group 1-5) post-birth deficit, we found that between 1981 and 2001 the contribution of late post-birth daughter deficit declined sharply, while the share of pre-birth daughter deficit rose sharply. Analysis of district-level data on births and infant mortality showed that daughter deficit is not limited to isolated pockets but occurs in more than two-thirds of the rural areas of the state. Pre-birth daughter deficit seems to account for the bulk of the estimated shortfall, suggesting that sex selective abortion may be far more widespread than female infanticide. Additionally, the discussion here along with evidence on the decline in the o- 6 sex ratio in other states clearly supports the view that the diagonal divide in sex ratios and daughter deficit in India is no longer valid.

\section{NOTES}

1 Based on an expected SRB of 952 and expected rates of male infant and child mortality, the lower limit for the o- 6 sex ratio in populations without any pre- or post-birth interference should be 952 .

2 Despite noting that areas with a normal SRB have "shrunk considerably in south India, as many districts in Karnataka, Andhra Pradesh and Tamil Nadu have crossed the threshold", Bhat and Zavier (2007: 2296), conclude that the SRB in south India is well within the normal range.

3 Previous papers on daughter elimination in Tamil Nadu include Soundarapandian (1985), George et al (1992), and Chunkath and Athreya (1997).

4 While there is no need to stop at age 5 , the data suggest that mortality rates for boys and girls are not very different in the age group 5-9. According to Planning Commission (2002:233) even in 1981 and 1991, mortality rate in the age group 5-9 in Tamil Nadu was lower for girls (2.9 and 1.8 in 1981 and 1991, respectively) than for boys ( 3 and 2.4 in 1981 and 1991, respectively).

5 Countries include, Australia (2004) 944, Canada (2003) 952, Chile (2003) 955, France (2004) 951, Germany (2004) 949, Guatemala (1999) 965, Italy (2003) 946, Japan (2004) 950, Kazakhstan (2003) 943, Morocco (2001) 952, Netherlands (2004) 955, Poland (2004) 942, Romania (2003) 940, Spain (2003) 942, United Kingdom (2003) 951, and Venezuela (2002) 932

6 Countries include, Australia (2004) 77, Canada (2003) 79, Chile (2003) 82, France (2004) 74, Germany (2004) 79, Guatemala (1999) 79, Italy (2003) 81, Japan (2004) 82, Kazakhstan (2004) 72, Morocco (2001) 83, Netherlands (2004) 71, Poland (2004) 77, Romania (2003) 72, Russia (2004) 72, Spain (2003) 80, United Kingdom (2003) 82, United States (2003) 76, and Venezuela (2001) 73.

7 Under 5 mortality rate is defined as the number of deaths by age 5 per 1,ooo live births while the IMR is defined as the number of deaths by age 1 per 1, ooo live births. Thus, the gap between the two provides information on the number of deaths between age 1 and 5 per 1,000 live births.

8 Other states are Arunachal Pradesh (rural-96o, urban-980), Daman and Diu (rural-916, urban-943), Delhi (rural-85o, urban-870), and Manipur (rural-956, urban-961).

9 If we work with IMR figures from SRS 1981 (Table 5, row 2), then the relative share of early and latepost-birth deficit would be different with early post-birth deficit playing a larger role as compared to the estimates in row 1 . Since we do not have SRS based estimates of U5MR we focus on the numbers in row 1.
10 NFHS-3 reports similar figures (see www.nfhsindia.org/nfhs3_national_report.html).

11 The assumption is extreme as the implication of a 20 point increase from the 0-1 sex ratio of 923 to a o-6 sex ratio of 942 , as in Table 5 , row 6 , is that under-5 mortality for males must be higher than under-5 mortality of females.

\section{REFERENCES}

Agnihotri, Satish (2003): "Survival of the Girl Child: Tunnelling Out of the Chkravyuha", Economic \& Political Weekly, 38(41): 4351-60.

Athreya, Venkatesh (1999): "A Report on the Vital Events Surveys", Chennai, Mimeo.

Bhaskar, V and Bishnupriya Gupta (2007): "India's Missing Girls: Biology, Customs, and Economic Development", Oxford Review of Economic Policy, 23(2): 221-38.

Bhat, Mari P N and A J Francis Zavier (2007): "Factors Influencing the Use of Prenatal Diagnostic Techniques and the Sex Ratio at Birth in India", Economic \& Political Weekly, 42(23): 2292-2303.

Chunkath, Sheela Rani and V B Athreya (1997): "Female Infanticide in Tamil Nadu-Some Evidence", Economic \& Political Weekly, 32(17): WS-21-28.

Dyson, Tim and Mick Moore (1983): "On Kinship Structure, Female Autonomy and Demographic Behaviour in India", Population and Development Review, 9(1): 35-6o.

George, Sabu, Rajaratnam Abel and Barbara Miller (1992): "Female Infanticide in Rural South India", Economic \& Political Weekly, 27 (22): 1153-56.

Goodkind, Daniel (1996): "On Substituting Sex Preference Strategies in East Asia: Does Prenatal Sex Selection Reduce Postnatal Discrimination?" Population and Development Review, 22 (1): 111-25.

James, W H (1996): "Evidence That Mammalian Sex Ratios at Birth Are Partially Controlled by Parental Hormone Levels at the Time of Conception", Journal of Theoretical Biology, 180: 271-86.

Jayaraj, D and S Subramanian (2004): "Women's Well-being and the Sex Ratio at Birth: Some Sug gestive Evidence from India", Journal of Develop ment Studies, 40(5): 91-119.

Jha, Prabhat, Rajesh Kumar, Priya Vasa, Neeraj Dhingra, Deva Thiruchelvam and Rahim Moineddin (2006): Low Male-To-Female Sex Ratio of Children Born in India: National Survey of 1.1 Million Households in The Lancet, Published online 9 January 2006, DOI:10.1016/So140-6736(o6) 67930-0, www.thelancet.com.

Johansson, Sten and Ola Nygren (1991): "The Missing Girls of China: A New Demographic Account", Population and Development Review, 17(1): 35-51.
Klasen, Stephan and Claudia Wink (2003): "Missing Women: Revisiting the Debate", Feminist Economics, 9(2-3): 263-99.

Miller, Barbara (1989): "Changing Patterns of Juvenile Sex Ratios in Rural India, 1961 to 1971 ", Economic \& Political Weekly, 24(22): 1229-36.

Oster, Emily (2005): "Hepatitis B and the Case of the Missing Women", Journal of Political Economy, $113(6): 1163-1216$.

Pandey, Arvind, Minja Kim Choe, Norman Y Luther, Damodar Sahu and Jagdish Chand (1998): Infant and Child Mortality in India, National Family Health Survey Subject Reports (Mumbai, India: International Institute for Population Sciences).

Patel, Tulsi, ed. (2007): Sex-selective Abortion in India: Gender, Society and New Reproductive Technologies (Delhi: Sage Publications).

Planning Commission (2002): National Human Development Report 2001. http://planningcommission. nic.in/reports/genrep/nhdrep/nhdreportf.htm.

Premi, M K (2001): “The Missing Girl Child", Economic \& Political Weekly, 36(21): 1875-80.

Ramachandran, K V and V A Deshpande (1964): "The Sex Ratio at Birth in India by Regions", Milbank Memorial Fund Quarterly, 42(2): 84-94.

Retherford, Robert D and T K Roy (2003): Factors Affecting Sex-Selective Abortion in India and 17 Major States, National Family Health Survey Subject Reports (Mumbai: International Institute for Population Sciences).

Sopher, D E (1980): “The Geographical Patterning of Culture in India" in D E Sopher (ed.), An Exploration of India: Geographical Perspectives on Society and Culture (London: Longman), pp 289-26.

Soundarapandian, A (1985): "Varadatchanaikkup payandu pen kuzhandaigalai kolgirargal", Junior Vikatan, 4 December (in Tamil).

Sudha, S and S Irudaya Rajan (2003): "Persistent Daughter Disadvantage: What Do Estimated Sex Ratios at Birth and Sex Ratios of Child Mortality Risk Reveal?" Economic \& Political Weekly, 38 (41): 4361-69.

United Nations (2004): United Nations Demographic Yearbook, http://unstats.un.org/unsd/demographic/ products/dyb

Visaria, P M (1967): "The Sex Ratio of the Population of India and Pakistan and Regional Variations during 1901-61" in A Bose (ed.), Patterns of Population Change in India, 1951-61 (Bombay: Allied Publishers).

Visaria, P M (1969): "The Sex Ratio of the Population of India", Monograph No 10, Census of India 1961, Office of the Registrar General, India.

Waldron, Ingrid (1983): "Sex Differences in Human Mortality: The Role of Genetic Factors", Social Science and Medicine, 17(6): 321-33. 